\title{
Herder e a metafísica
}

\author{
Oliver Tolle
}

Professor adjunto I do Departamento de Filosofia da UFS 

Na "Introdução" de seus Cursos de estética, Hegel de imediato recusa a tese de que a correta consideração da arte seja derivada de uma "ciência do sentido, da sensação". Atento à história da estética como disciplina filosófica, Hegel recorda que ela "teve o seu nascimento na escola de Wolff, na época em que na Alemanha as obras de arte eram consideradas em vista das sensações que deveriam provocar". Q Qual o exato motivo desta recusa? Não teria Hegel simplesmente evitado a dificuldade de que uma correta investigação do objeto artístico passa também pela caracterização de como ele afeta os órgãos dos sentidos? Também Kant, numa célebre nota de rodapé da Crítica da razão pura, descartou rapidamente a estética alemã como "crítica do gosto":

Esta denominação tem por fundamento uma esperança malograda do excelente analista Baumgarten, que tentou submeter a princípios racionais o julgamento crítico do belo, elevando as suas regras à dignidade da ciência. Mas esse esforço foi vão².

Sem dúvida, entre os anos de 1730 e 1780 um grande número de autores debruçou-se na Alemanha sobre a questão da sensibilidade: não só Baumgarten, mas também Meier, Mendelssohn, Hamann, Sulzer, para não mencionar outros, dedicaram-se a uma ciência do sensivel 3 . Em comum esses autores tinham a proposta

1 G. W. F. HEGEL. Cursos de estética. v. 1. Trad. de M. A. Werle. São Paulo: Edusp, 1999 , p. 27.

2 I. KANT. Crítica da razão pura. Trad. de M. P. dos Santos, A. F. Morujão. Lisboa: Fundação Calouste Gulbenkian, 1989, p. 62, nota.

3 Segue-se uma pequena seleção de obras desse período relativas ao tema: Baumgarten publicará o primeiro volume de sua Aesthetica - "ciência do sensível" - em 1750, mas os fundamentos desta já se encontravam na Metaphysica de 1739. Como as obras estavam em latim, elas destinavam-se basicamente ao público acadêmico. Já entre os anos de 1748 e 1750, seu discípulo Georg Friedrich Meier publicará em alemão a obra Anfangsgründe aller schönen Künste und Wissenschaften (Princípios de todas as belas-artes e ciências), que consiste numa compilação de anotações de aulas proferidas por Baumgarten e que contribuiu para divulgar suas ideias. Em 1755 surgirão as Briefe über die Empfindungen (Cartas sobre as sensações), de Moses Mendelssohn, autor também de Betrachtungen über die Quellen und die Verbindungen der schönen Künste und Wissenschaften (Considerações sobre as fontes e relações entre as belas-artes e 
de reconduzir a filosofia ao concreto e efetivo; esse impulso provocou um novo renascimento dos poetas e retores da Antiguidade grega e latina, mas com o comprometimento de adequar sua produção às questões filosóficas da modernidade.

Herder desempenha um papel particularmente importante nesse esforço. Como talvez o último a propor uma ciência do sensível - seus textos a esse respeito foram redigidos no período entre 1760 e 1780 -, ele se encontra justamente no hiato entre o começo da decadência da metafísica na Alemanha e o surgimento da filosofia crítica4. Descrente de uma solução para as querelas metafísicas de seus antecessores, mas também não satisfeito com as implicações materialistas de seus antagonistas, ele desenvolve o projeto radical de remover completamente da investigação filosófica seus pressupostos metafísicos e sua propensão a tratar de Deus antes do humano:

Preocupa-me muito pouco a abstração supraterrena, que põe tudo o que

ciências), de 1757. Johann Georg Sulzer, que ficará famoso pelo dicionário Allgemeine Theorie der schönen Künste (Teoria universal das belas-artes) (1771-4), também se posicionará na discussão sobre o sensível em Gedanken über den Ursprung der Wissenschaften und schönen Künste (Pensamentos sobre a origem das ciências e belas-artes), de 1762. Por fim, vale destacar também a obra do mestre de Herder, Johann Georg Hamann, Aesthetica in nuce, de 1760 .

4 Já se tornou lugar-comum entre os comentadores denunciar a pouca atenção que a crítica especializada lançou sobre esse período. A recente tradução integral da Estética de Baumgarten para o alemão e as diversas traduções de coletâneas sobre os textos epistemológicos e estéticos de Herder para o inglês certamente ampliaram essa impressão. Nesse sentido, ao chamar a atenção para a importância de Herder como filósofo, o comentador Forster queixa-se recentemente do descaso com que comentadores contemporâneos trataram da contribuição de seu pensamento para a filosofia. Entre os diversos motivos que fornece para isso, ele alega que nem mesmo em seu tempo a importância de Herder foi devidamente considerada: "He fell out, in one way or another, with almost everyone who was anyone in his own day, including his former teacher Kant, his former follower Goethe, Schiller, Fichte, and the Schlegels. As a result, he tended to be widely read and borrowed from by the generation(s) that succeeded him but rarely credited" (M. N. FORSTER. Herder's Importance as a Philosopher. In: M. N. FORSTER. After Herder. Oxford: Oxford University Press, 2010, p. 97, nota). Essa queixa certamente tem seu fundamento, mas ela ignora que Herder em nenhum momento deixou de ser criticado em seu tempo, ainda que as praxes historiográficas de dar nome a seus objetos de crítica não sejam uma característica dos filósofos do final do XVIII, obrigando assim o comentador a identificar os criticados. 
se denomina círculo de nosso pensamento e sensação em não sei que trono da divindade, criando ali mundos de palavras e dirigindo-se além de tudo o que é possível e efetivo5.

Estamos aqui diante de um antidogmatismo, o qual, por si mesmo, não ofereceria muito interesse e poderia até mesmo causar enfado a leitores acostumados aos eventos intelectuais do século XVIII, não fosse ele também marcadamente contrário ao Iluminismo. Em Herder, a crítica à metafísica anda de mão em mão com o juízo de que a formação iluminista privilegia tão somente o intelecto, e, portanto, despreza o homem integral, constituído também de uma complexidade infinita de paixões e sensações ${ }^{6}$.

$\mathrm{O}$ presente trabalho propõe-se a refazer os principais caminhos que conduzem Herder para além da abstração metafísica e, como se tentará mostrar, tornam seu pensamento a expressão tardia da crença no potencial de uma educação que subordina a razão à sensibilidade. Mas também é resultado do trabalho constatar que, a despeito do reconhecimento de um domínio próprio ao sensível, Herder, assim como Baumgarten, concluem com a expectativa de uma fisiognomia, o resultado mais maduro da ciência do sensível7. Ora, esse é o perigo daquele que se aproxima do senso comum e, ao validar seus conteúdos, é obrigado a afirmar a harmonia entre órgãos dos sentidos e o efetivo, aproximando-se assim novamente da metafísica de que tanto queria escapar.

5 J. G. HERDER. Schriften zu Philosophie, Literatur, Kunst und Altertum (1774-1787). Bonn: DKV, 1998, p. 330.

6 "A filosofia e a pedagogia do século das Luzes extirpam pela raiz a possibilidade de cultivo das aptidões dos indivíduos, porque se voltam exclusivamente para o aperfeiçoamento precoce de suas faculdades intelectuais. A essa concepção de um homem hipertrofiado em sua razão, Herder opõe o ideal de uma formação completa, que leve em conta todo o indivíduo" (M. SUZUKI. A ciência simbólica do mundo. In: A. NOVAES (Org.). Poetas que pensaram o mundo. São Paulo: Companhia das Letras, 2005, p. 203).

7 Para Herder, "a fisiognomia, no sentido mais amplo, isto é, a fisiologia psicológica, é a parte mais importante da sabedoria mundana [Weltweisheit]" (J. G. HERDER. Schriften zu Philosophie..., op. cit., p. 1120). 
No panegírico Monumento a Baumgarten, Herder declara que, "dentre todas as explicações da poesia que pretendem compreender a sua essência em um conceito", a baumgartiana é a que lhe parece a "mais filosófica". Ela conseguiu o feito de ir além da tese aristotélica da imitação e de seu então representante, o abade Batteux. Com base na noção da poesia como discurso sensivel perfeito, Baumgarten, "com poucas palavras", indicou o "máximo que se pode ver até o fundamento da poética"s. Tarefa de não pequena importância, uma vez que, na época em que Baumgarten empreendeu a redação de sua Estética, considerava-se não haver "nada mais contraditório do que gosto e contemplação filosófica" ". Com o critério de demarcação do conhecimento sensível - isto é, de que esse conhecimento caracteriza-se pela imediatez (ausência de reflexão) -, Baumgarten ampliou o território da filosofia para além da demonstração, conferindo validade também àquilo que se encontra circunscrito ao âmbito das faculdades cognitivas inferiores (órgãos dos sentidos). Como se sabe, Leibniz e Wolff já haviam caminhado nessa direção, mas a eles faltara o passo seguinte, ou seja, unir a fundamentação do conhecimento sensível a uma teoria das artes ${ }^{10}$. Mas essa não foi a única consequência: ao aproximar teoria do conhecimento e teoria do belo, a arte passou a ser o correlato direto da vida, e, principalmente no caso de Baumgarten, a estética converteu-se no lugar em que a filosofia da vida poderia ganhar forma e, com base em seus exemplos, fornecer um panorama de sua diversidade.

Ora, é comum aos filósofos que pensaram a questão da sen-

8 J. G. HERDER. Frühe Schriften 1764-1772. Bonn: BDK, 1985, p. 683. 9 Id., ibid., p. 682.

10 Basicamente, Leibniz é responsável por conferir verdade ao conhecimento sensível. Wolff, por seu lado, estabelece um âmbito cognitivo exclusivo à sensibilidade, composto de faculdades cognitivas próprias, em oposição às faculdades superiores, racionais. 
sibilidade nesse período na Alemanha apontar a arte como a sua expressão mais elevada. No entender de Mendelssohn, por exemplo, a investigação da sensibilidade é facilitada quando aplicada à arte:

Portanto, devemos analisar cuidadosamente os fenômenos em que os mecanismos de nossa alma se encontram na maior movimentação e confrontá-los com a teoria, para lançar uma luz sobre ela e expandir os seus limites por meio de novas descobertas. Mas em que fenômenos os mecanismos da alma estão em maior movimento senão nos efeitos das belas-artes?"1.

Herder também seguirá essa regra de que a investigação das belas-artes e da sensibilidade é guiada pelo mesmo princípio. Assim como Baumgarten subordinou a estética diretamente à psicologia, Herder tomará essa ciência - psicologia ou doutrina da alma (Seelenlehre) ${ }^{12}$ - como ponto de partida, com a diferença de que o critério de demarcação baumgartiano da ciência do sensível lhe parecerá demasiado "bárbaro", prejudicado pelo compromisso com a "terminologia wolffiana" e por um latim extremamente erudito e preso ainda a questões propostas por filosofias de outros tempos. Ele chama a atenção, todavia, para o fato de que é preciso reconhecer que, entre os metafísicos, Leibniz e Baumgarten foram aqueles que "olharam mais profundamente na alma" e que "mais avançaram na meta de obter observações universais" Mas Herder lembra que a "cultura filosófica" de sua época "é diferente" ${ }^{14}$. Ela não confere mais tanta importância às elucubrações dos metafísicos e, portanto, não há sentido em dar respostas a questões que não precisam mais ser respondidas.

11 M. MENDELSSOHN. Betrachtungen über die Quellen und die Verbindungen der schönen Künste und Wissenschaften. Bibliothek der schönen Wissenschaften und der freyen Künste, v. 1, cad. 2, Leipzig, 1757, p. 232.

12 Seelenlehre é, a partir de Wolff, a tradução alemã para o latino psychologia.

13 J. G. HERDER. Frühe Schriften..., op. cit., p. 689.

${ }_{14}$ Id., ibid., p. 690. 
Pode-se simplesmente abandonar as metafísicas para pôr em seu lugar a ciência da psicologia? É preciso observar que Herder em nenhum momento se posicionará totalmente contra os resultados da filosofia, mas apenas contra a interminável discussão que resulta da investigação de seus pressupostos ou fundamentos. $\mathrm{Na}$ década de 1770, Herder empreende três redações sobre o tema de conhecimento e sensação ${ }^{15}$, em que indica a insuficiência do sistema leibniziano da harmonia preestabelecida. Esse sistema, que ficou conhecido pela analogia dos dois relógios que, em sincronia, operam no andar da alma e no andar do corpo, "é verdadeiro, mas incompleto: ele não explica o que deve explicar"16. Em vez de consolidar, como desejável, a interdependência entre alma e corpo, o excessivo didatismo de Leibniz teria perpetuado a separação entre razão e sensibilidade, muito em virtude de seu respeito histórico às categorias escolásticas.

A metafísica tornou-se um mero jogo de tabuleiro. As peças são sempre as mesmas: "ideias obscuras e claras, nítidas e confusas; conhecimento em si mesmo e fora de si mesmo"17. Acredita-se que, mudando-as de lugar, obter-se-ão novos significados, mas em virtude de seu uso repetido elas já perderam o contato com a origem. No fundo, não passam de "palavras ocas"; elas são como os "números", completamente indiferentes em relação aos objetos que enumeram. Comportando-se assim, a filosofia certamente alcançará a perfeição, mas uma perfeição abstrata, como a da

15 Uebers Erkennen und Empfinden in der Menschlichen Seele (Sobre conhecimento e sensação na alma humana) (1774), Vom Erkennen und Empfinden, den zwo Hauptkräften der Menschlichen Seele (Acerca do conhecimento e da sensação, as duas principais forças da alma humana) (1775) e Vom Erkennen und Empfinden der menschlichen Seele. Bemerkungen und Träume (Acerca do conhecimento e da sensação da alma humana. Observações e sonhos) (1778).

16 J. G. HERDER. Schriften zu Philosophie..., op. cit., p. 1109.

17 Id., ibid., p. 340. 
matemática, do "contador diante de seus números", em que se "podem tirar conclusões sem pensar - que todas as musas nos protejam dessa filosofia!"18. Essa comparação tem a sua história. Já em suas Meditações sobre a natureza do poema, Baumgarten, citando Cícero, advertira sobre o risco de confundir a atividade do filósofo com a do geômetra ${ }^{19}$. Trata-se novamente uma crítica ao mecanicismo cartesiano, crítica que naqueles dias já se convertera em modismo? Sem dúvida, mas Herder é, como muitos outros em sua época, um leitor atento das Paixões da alma e, assim como o autor destas, exige uma explicação filosófica adequada à estreita relação entre razão e sensibilidade evidenciada pela experiência.

O que então dizer das ideias inatas, problemática que fornecera o tom das discussões filosóficas dos últimos cinquenta anos? Para Herder, é preciso conceder a Locke que as "percepções individuais não são inatas" à alma e que, por conseguinte, a alma não pode e não deve "estudar em si mesma fatos históricos, símbolos, etc." ${ }^{20}$, como se esses conteúdos sensoriais pudessem ser explorados em um âmbito anterior à experiência. Os motivos de Herder são todavia outros. Para ele, não podemos afirmar a existência de ideias inatas sobre percepções individuais principalmente pelo fato de que a alma não conhece senão obscura e confusamente as imagens do corpo. Ela "não sabe como o seu Eu chegou aos

18 J. G. HERDER. Schriften zu Philosophie..., op. cit., p. 340.

19 "Esta é o modo dos matemáticos, mas não dos filósofos. Pois quando os matemáticos querem realizar algo e isto depende de realizações anteriores, então o consideram como resolvido e demonstram e explicam apenas aquilo que não tinha sido tratado anteriormente. Mas quando o filósofo tem algo em suas mãos, então ele leva em consideração tudo o que tenha alguma relação com isso, mesmo que já tenha sido explicado em outra parte" (Cícero, Tusc. Quaest. lib. V. p. m. 250; citado em A. BAUMGARTEN. Meditationes philosophicae de nonnullis ad poema pertinentibus. \$2. ILIESI Digital Edition. Disponível em: <http://modernsource.daphnet.org >.).

20 J. G. HERDER. Schriften zu Philosophie..., op. cit., p. 1107. 
símbolos que sempre a acompanharam" ${ }^{21}$. Constitui um hábito escolar pernicioso exigir que a suposição da existência das ideias inatas obrigue o filósofo a indicar essas mesmas ideias, como se elas fossem sensações ou percepções.

Mas é preciso tomar certo cuidado aqui. Herder lembra que quando metafísicos falam de ideias inatas, em nenhum momento querem, com elas, fazer referência a um conhecimento a priori daquilo que só pode ser conhecido pelos sentidos. A raiz de toda a disputa reside em um mal-entendido. O fato é que Leibniz não "se expressou de maneira suficientemente satisfatória", aliás uma dificuldade que atingiu também Descartes, Espinosa, Shaftesbury e Platão, mas, a bem da verdade, é preciso desculpá-los, pois todo aquele "que tenda para esse lado sempre dirá disparates, ainda que esses sábios pouco pensassem com isso em disparates" ${ }^{22}$. E no que consiste exatamente esse disparate? Por força de tomar-se a alma e o corpo como unidades heterogêneas, faz-se uma afirmação que a experiência contraria a todo momento. Alma e corpo são esferas em constante interação, de tal modo que mal somos capazes de identificar onde começa uma e onde termina a outra. Isso não significa, contudo, que se possa aprovar a noção de um corpo desprovido de alma, formado unicamente por experiência e sensação.

Se está em nossa alma a força de conhecer segundo a imagem da divindade, isto é, de encontrar a verdade e a bondade e transformá-las em sua essência, então ela não é uma tabula rasa, como tampouco o nosso corpo o é desde o primeiro instante de sua formação, e acredito que não haja imagem mais informe em que se possa pensar ${ }^{23}$.

21 J. G. HERDER. Schriften zu Philosophie..., op. cit., p. 1108.

22 Id., ibid., op. cit., p. 1109. Posição semelhante encontra-se na "psicologia" de Baumgarten. A esse respeito, conferir O. TOLLE. Luz estética: a ciência do sensível de Baumgarten entre a arte e a iluminação. 8/5/2008. Tese (Doutorado em Filosofia) - Faculdade de Filosofia, Letras e Ciências Humanas, Universidade de São Paulo,

São Paulo, 2008, p. 35-6. 23 Id., ibid., op. cit., p. 1106-7. 
Estão então equivocados os autores ao afirmarem a sua separação? De modo algum, cometem erro ainda mais grave aqueles que tomam a alma como corpo ou o corpo como alma. Também eles dizem disparates:

Se alguém afirmasse que a alma, como um espírito imaterial, atuasse como um corpo sobre o corpo por meio de impulso, choque, então ele teria dito disparates. Ele supôs de uma só vez que a alma é material e imaterial, e a esse respeito não se deve gastar nenhuma palavra ${ }^{24}$.

Adquirimos aqui a possibilidade de pôr materialistas e idealistas lado a lado. Ambos se distanciam do objetivo da filosofia, a saber, o de encontrar explicações para o efetivo. Ultrapassando o âmbito deste último, convertem-se em mero objeto de disputas acadêmicas. Pois, na medida em que o indivíduo busca constantemente a harmonia entre alma e corpo, por um lado, há ideias inatas; por outro, nenhuma percepção é inata. A ênfase excessiva em qualquer um dos lados gera absurdos. Feito de carne, vísceras, tendões e músculos, o corpo é a única referência válida. Feito esse reparo, novamente há lugar para Deus: "A lei de Deus já foi escrita com fogo no coração; nele ardem forças, centelhas vivas para transformar tudo o que puder em sua essência, para reconhecer a imagem da divindade" 25 .

Assim, o sistema da influência apresentado por Leibniz está longe de ser equivocado. Os outros dois sistemas, que consideram ou a alma como corpo ou o corpo como alma, conduzem ao absurdo de tomar duas realidades como uma só. Ora, com Herder encontramo-nos agora inteiramente no terreno da psicologia (Seelenlehre), ao qual foi reduzido todo o conteúdo das metafísicas de orientação leibniziana. Não se trata, sem dúvida, de simplesmente 
recusar as ciências que lhe estão diretamente subordinadas, como a ontologia ou a cosmologia, mas de reconhecer que, embora corretas, elas precisam ser comprovadas no âmbito da psicologia.

Desde Wolff essa conclusão já era válida para o âmbito da psychologia; a novidade aqui é que Herder torna essa ciência o único âmbito de consideração filosófica propriamente dito. Para ele, "a priori nada sabemos sobre a alma", pois ela só se torna acessível na mediação com o corpo, o qual é fonte pura de sensações: “[...] cada um conhece apenas segundo a sua sensação. Ele representa para si o mundo apenas segundo as fórmulas que o corpo lhe transmitiu. Ele sente apenas no horizonte fixo de seu corpo" ${ }^{26}$.

Ora, esse deslocamento para o corpo terá a vantagem de não acarretar a excessiva subjetivação de que posteriormente se acusará o idealismo transcendental como um todo. Ao contrário, com ele procura-se justamente romper a fronteira entre interioridade e exterioridade: "Sem qualquer mística e no entendimento filosófico mais preciso, o homem interior é completamente um habitante do exterior: e o exterior é apenas o invólucro do interior [... ${ }^{227}$. Assim como falta ao homem a capacidade de afirmar a motivação da existência dos corpos externos, também lhe é impedida a compreensão da formação da sensação na interioridade do corpo. Ora, por um lado, para falarmos com propriedade de como os corpos foram criados, a metafísica se tornaria necessária (e com ela uma cosmologia); e, por outro, foi a tentativa de explicação da estreita junção entre corpo e alma que levou Descartes a supor "que o Criador pendurou [a alma] na glândula pineal"28. Não está em causa, todavia, se os corpos são existentes ou não. Herder procura

26 J. G. HERDER. Schriften zu Philosophie..., op. cit., p. 1111. Ecoa aqui a proposição "a alma é uma força que representa o mundo segundo a posição de seu corpo", que define o âmbito da "psicologia empírica" na Metafísica de A. BAUMGARTEN (Metaphysica, $\ 5$ 12. Ed. online do Bonner Kant-Korpus. Disponível em: $<\mathrm{http}: / / \mathrm{www}$. korpora.org/Kant/>).

27 J. G. HERDER. Schriften zu Philosophie.., op. cit., p. 1107.

28 Id., ibid., p. 1108. 
evitar afirmações que conduzam a uma negação da alma ou do corpo. Para ele, ambos os caminhos são equivocados e extrapolam as capacidades cognitivas humanas ${ }^{29}$.

Se os termos "corpo" e "alma" se encontram por demais enredados em questões supraterrenas, não seria melhor substituí-los por outros, mais conformes às necessidades da psicologia? Como vimos, não se trata de abandonar completamente a dualidade, mas apenas de evitar contrassensos. A solução de Herder é inserir um outro par de conceitos, conhecimento e sensação, que acarreta uma oposição menos rígida que a anterior. Na verdade, mesmo no uso corriqueiro dessas palavras, só é "até certo grau aparente a separação entre conhecimento e sensação"3o.

Sem a referência de princípios universais, resta, portanto, a tarefa de investigar a diversidade de modificações que o corpo produz na alma, e vice-versa. Só há três caminhos que conduzem a esse conhecimento: "relatos biográficos, observações de médicos e amigos, divinações de poetas" ${ }^{31}$. Eles têm apenas um objetivo: o bem-estar da alma e do corpo. E justamente nisso reside a destinação do homem: acumular informações sobre os mecanismos e eventos que propiciam esse bem-estar. Uma tarefa que a humanidade praticamente ignorou até então:

Tivesse um indivíduo a sinceridade e lealdade de descrever a si mesmo, tal como se conhece e sente: tivesse ele coragem suficiente para olhar no

29 Ora, seria uma injustiça com Leibniz esquecer que a sua hipótese da harmonia preestabelecida, aliás, uma hipótese metafísica demonstrada, foi concebida dentro desses mesmos limites do conhecimento humano. É o que lemos em seu Discurso de metafísica: "Recorro a essas comparações [metafísicas], para esboçar alguma imperfeita semelhança com a sabedoria divina e dizer algo a fim de poder, pelo menos, elevar o nosso espírito a conceber de algum modo o que não se saberia bem exprimir. Mas de maneira alguma pretendo explicar assim o grande mistério de que depende todo o universo" (G. LEIBNIZ. Monadologia, Discurso de metafísica e outros textos. Trad. de M. Chaui et al. São Paulo: Abril, 1983, p. 123).

30 J. G. HERDER. Schriften zu Philosophie..., op. cit., p. 1118. Obviamente, está afastada aqui qualquer possibilidade de irracionalismo: "A sensação não é contrária à razão, mas apenas o esquema sensível e o órgão desta” (id., ibid., p. 1104).

${ }_{31}$ Id., ibid., p. 340. 
abismo da reminiscência platônica e não negar nada a si mesmo; coragem suficiente para investigar toda a estrutura do seu corpo vivo ao longo de sua vida inteira [...], então que fisiognomia cheia de vida resultaria disso, sem dúvida mais profunda que o contorno da testa e do nariz ${ }^{32}$.

Pode-se acusar Herder de ter uma compreensão equivocada do sistema da harmonia preestabelecida? Pois já segundo a sistematização empreendida por Wolff, a cosmologia não trata da relação entre corpo e alma, mas justamente da relação entre mônadas, os verdadeiros átomos da natureza. A esse propósito, veja-se, por exemplo, a maneira com que Baumgarten define o âmbito da cosmologia: "ciência dos predicados universais do mundo". Esta se opõe à psicologia: "ciência dos predicados universais da alma”33. Certamente, para Baumgarten, por tratar da relação entre as mônadas, desprovidas de "janelas", isto é, de comunicação entre si, a cosmologia serve de base para a psicologia. Mas apenas porque, na mesma medida em que garante o acordo entre as mônadas, ela livra a psicologia da tarefa de demonstrar a maneira com que os corpos agem uns sobre os outros.

Ora, quando Herder exige que a compreensão da relação entre corpos seja derivada unicamente da relação entre alma e corpo, a qual constitui o limite do conhecimento humano, ele fornece uma outra configuração para a explicação cosmológica. Já não se trata mais de pressupor uma ordem divina para mônadas ou corpos, mas verificar que tipo de ordem pode-se concluir com base na interação entre pensamento e sensação. Nesse ponto, a metafísica ultrapassa todas as possibilidades cognitivas humanas, o que se torna particularmente evidente quando se observa que a metafísica privilegia, como explicação, a atemporalidade do divi- 
no em contraposição ao criado. Um exemplo típico dos excessos metafísicos: "Quem compreende como surgiram espaço e tempo, tempo e coisas singulares no infinito destituído de espaço e tempo? Ninguém!"34. Ao contrário, quando se quer considerar o universo, o ponto de partida deve ser o corpo humano. É ele que fornece "uma fórmula do cosmos na imagem mais simples e facilmente asssimilável”. Sem dúvida, há uma harmonia preestabelecida, mas ela só pode ser fundamentada com base na disposição do universo em relação ao corpo. É graças à harmonia que os órgãos dos sentidos podem perceber outros corpos e posicionar-se adequadamente em relação a eles:

[...] porque não podemos, com base no universo e por meio do universo, explicar e procurar a natureza nem da força do pensamento nem das partes da percepção e do corpo. E já por esse motivo todos os sistemas sobre a ligação do corpo e da alma são vãos ${ }^{35}$.

Para Herder, os sentidos do tato e da audição são aqueles que mais nos aproximam da efetividade do mundo. Assim, se quisermos compreender as categorias do espaço e do tempo, é com base nesses sentidos que devemos construir os seus conceitos. Suponhamos que sejamos constituídos apenas de força, tato e audição, então:

[...] é nesses três conceitos que residiria toda a metafísica de espaço, tempo e força:

A força seria: eu penso e, por esse motivo, atuo no universo e sou corpo. Espaço: eu sinto pelo tato, isto é, eu penso em um âmbito delimitado. Tempo: eu ouço, isto é, eu penso uma coisa depois da outra ${ }^{36}$.

Assim, se se quiser ter uma compreensão do universo, ela

34 J. G. HERDER. Schriften zu Philosophie..., op. cit., p. 1094.

35 Id., ibid., p. 235.

36 Id., ibid., op. cit., p. 236. 
deve começar por aí, com base na origem sensorial humana e não na possível situação extratemporal e espacial de Deus. Em vez de posicionar a divindade em um espaço infinito, portanto, "espaço nenhum" - artifício que nasce tão somente da "negação de nossa limitação" e que, por consequência, nos obrigaria a fazer afirmações insólitas como "Deus não sabe o que é o espaço"37 -, a estratégia do filósofo deve estar rigorosamente circunscrita às suas capacidades cognitivas.

A antropologia torna-se assim uma necessidade metodológica para minimizar o efeito negativo da abstração. Ciência das analogias, ela toma o homem como centro e mede o restante em relação a ele: "o que nós sabemos, sabemos apenas com referência à criatura em relação a nós e a nós em relação ao criador" ${ }^{3}$. Mas a antropologia não é muito diferente das metafísicas. A sua vantagem reside em reconhecer que "a primeira concepção da verdade" se dá no homem, e não em Deus. Mas ambas se valem de linguagens imagéticas e figurativas. Nesse sentido, apesar de seus excessos, os metafísicos encontraram uma forma para falar do mundo. Até mesmo aqueles "metafísicos que bradaram contra a linguagem figurativa” e acreditaram ter ultrapassado seus limites não compreenderam que seu discurso também é feito de analogias. Assim, mesmo que "contra a sua vontade", Leibniz e Newton foram poetas. As suas cosmologias equiparam-se aos grandes poemas sobre a criação do mundo, em que também se encontravam mescladas a física e metafísica. Diante disso, não é de estranhar-se que Herder afirme a superioridade da poesia em relação à filosofia: "Acredito [...] que Homero e Sófocles, Dante, Shakespeare e Klopstock forneceram mais material para a psicologia e para o conhecimento do homem do que mesmo os Aristóteles e Leibniz de todos os povos e épocas"39.

37 J. G. HERDER. Schriften zu Philosophie..., op. cit., p. 237.

$3^{8}$ Id., ibid., p. 238.

39 Id., ibid., p. 331. 
Presenciamos em Herder uma ampla revisão conceitual. Em certo sentido, é correto afirmar que depois dela não se sustentam mais as antigas estruturas do discurso metafísico. Isso, porém, não se deve a uma pretensa falsidade das metafísicas, mas sim a que elas acabam sempre por nos afastar do principal, isto é, de que as fórmulas de apreensão do mundo só podem ser obtidas por meio da sensação. Nenhum universal pode substituir a experiência cotidiana, a qual consiste no esforço sempre reiterado de consumar a harmonia entre alma e corpo. Mas o que resta então da metafísica? Para Leibniz, a certeza da harmonia universal era o coroamento da tese do melhor dos mundos possíveis. A sua validade estendia-se a todos os âmbitos do conhecimento humano, o que quer dizer a todas as variantes da metafísica: ontologia, cosmologia, teologia e psicologia. Apenas esta última interessa a Herder, porque todas as outras são demasiado abstratas e de reduzida aplicabilidade.

A harmonia permanece, todavia, porque há conformidade entre os órgãos sensíveis e os objetos que entram em seu campo perceptivo. Se não houvesse harmonia, o mundo seria não apenas confuso, mas um obstáculo definitivo às possibilidades cognitivas, definidas antes de tudo pela configuração de cada um dos órgãos. A alma sente essa harmonia como prazer, um bem-estar que percorre todo o corpo e garante a ela que está interagindo adequadamente com o mundo. Mas então não seria pertinente uma explicação metafísica para dar ordem a esse caos perceptivo? Para Herder, a garantia leibniziana do melhor dos mundos possíveis apenas com muita dificuldade pode ser transferida para o terreno da psicologia ou da fisiologia psicológica. Seu valor é antes de tudo figurado, imagético, e nesse sentido ela é "uma nova imagem, uma analogia, um símile extraordinário”40. A psicologia 
ou a fisiologia psicológica são ciências menos tortuosas, com elas se espera que a alma se torne "não apenas mais leve e intuível", mas também obtenha "mais perspectivas do universo" ${ }^{4}$. A tarefa do pensamento é aproximar a alma da vida. Os conceitos e termos metafísicos "são demasiado indeterminados" e vagos para cumprir satisfatoriamente com esse objetivo. O homem quer ter não só "algo determinado para pensar diante de cada palavra, mas também um novo significado em cada nova ocorrência dessa palavra"4².

Voltemos a nosso ponto de partida. Podemos dizer agora que, pelo menos em parte, se justifica aquela recusa da ciência da sensação presente em Kant e Hegel. Apesar de orientada por um princípio vital e orgânico, avesso a qualquer universalidade, essa ciência precisa ser simultaneamente psicologia e fisiognomia. E nessa medida ela não considera a vida como fenômeno, mas como coisa em si³ . A explicação psicológica não é capaz de encontrar o fundamento da harmonia e assim ela acredita reconhecer na forma externa do mundo uma linguagem apropriada ao seu corpo. Mas é esse justamente o seu remédio contra a metafísica, isto é, torná-la a mais concreta possível.

\section{Bibliografia}

BAUMGARTEN, A. Metaphysica. Ed. online do Bonner Kant-Korpus. Disponível em: <http://www.korpora.org/Kant/>. Acesso em: jan. 2013.

41 Id., ibid., p. 1120.

42 Id., ibid., p. 331.

43 G. W. F. HEGEL. Fenomenologia do espirito. Trad. de P. Menezes. Petrópolis (RJ): Vozes, 2003, \&315. 
BAUMGARTEN, A. Meditationes philosophicae de nonnullis ad poema pertinentibus. ILIESI Digital Edition. Disponível em: $<$ http://modernsource.daphnet.org $>$. Acesso em: jan. 2013. BERLIN, I. Three Critics of the Enlightenment: Vico, Hamann, Herder. Princeton (NJ): Princeton University Press, 1997.

FORSTER, M. N. Herder's Importance as a Philosopher. In: . After Herder. Oxford: Oxford University Press, 2010.

HEGEL, G. W. F. Cursos de estética. v. 1. Trad. de M. A. Werle. São Paulo: Edusp, 1999.

. Fenomenologia do espírito. Trad. de P. Menezes. Petrópolis $(\mathrm{RJ})$ : Vozes, 2003.

HERDER, J. G. Frühe Schriften 1764-1772. Bonn: BDK, 1985.

Org. por U. Gaier. (Werke in zehn Bänden, v. 1). . Schriften zu Philosophie, Literatur, Kunst und Altertum (17741787). Bonn: DKV, 1998. Org. por J. Brummack, M. Bollacher. KANT, I. Crítica da razão pura. Trad. de M. P. dos Santos, A. F. Morujão. Lisboa: Fundação Calouste Gulbenkian, 1989.

LEIBNIZ, G. W. Monadologia, Discurso de metafísica e outros textos. Trad. de M. Chaui et al. 2. ed. São Paulo: Abril, 1983. 237 p. (Col. Os Pensadores).

MENDELSSOHN, M. Betrachtungen über die Quellen und die Verbindungen der schönen Künste und Wissenschaften. Bibliothek der schönen Wissenschaften und der freyen Künste, v. 1, cad. 2, Leipzig, 1757, p. 231-68. Disponível em: <http:// www.ub.uni-bielefeld.de/cgi-bin/neubutton.cgi?pfad=/diglib/aufkl/ bibschoewiss/130571\&seite $=00000244$. TIF $>$. Acesso em: jan. 2013.

SIMON, J. Herder and the Problematization of Metaphysics. In: Herder Today: Contributions from the International Herder Conference, Nov. 5-8, 1987. Nova York: De Gruyter, 1990, p. 108-125. Ed. por K. Mueller-Vollmer.

SUZUKI, M. A ciência simbólica do mundo. In: NOVAES, A. (Org.). Poetas que pensaram o mundo. São Paulo: Companhia das Letras, 2005, p. 199-224. 
TOLLE, O. Luz estética: a ciência do sensivel de Baumgarten entre a arte e a iluminação. 8/5/2008. Tese (Doutorado em Filosofia) - Faculdade de Filosofia, Letras e Ciências Humanas, Universidade de São Paulo, São Paulo, 2008. Disponível em: <http://www.teses.usp.br/teses/disponiveis/8/8133/tde03062008-203027/pt-br.php>. Acesso em: jan. 2013.

TODOROV, T. Teorias do símbolo. Trad. de E. A. Dobránszky. Campinas (SP): Papirus, 1996. 